\title{
Research Article \\ Thyroid autoimmunity among type 2 diabetes mellitus: assessing anti-thyroid peroxidase (anti-TPO) antibodies
}

\author{
Narendra Kumar Sah ${ }^{1}$, Saurabh Kumar Deo ${ }^{2}$, Harpreet Kaur Walia ${ }^{3 *}$, Alka Singh ${ }^{4}$, Suvarna Prasad $^{5}$, Kiranjeet Kaur $^{6}$ \\ ${ }^{1}$ Assistant Professor, ${ }^{3}$ Associate Professor, ${ }^{4}$ Professor \& Head, ${ }^{6}$ Professor, Department of Biochemistry, Maharishi \\ Markandeshwar, Medical College \& Hospital, Kumarhatti-Solan, 173229, H.P., India \\ ${ }^{2}$ Assistant Professor, Department of Biochemistry, Adesh Medical College \& Hospital, Mohri, Kurukshetra, 136135, Haryana, \\ India \\ ${ }^{5}$ Professor \& Head, Department of Biochemistry, Maharishi Markandeshwar Institute of Medical Sciences \& Research, \\ Mullana-Ambala, 133203, Haryana, India
}

(Received: July $2021 \quad$ Revised: October $2021 \quad$ Accepted: November 2021)

Corresponding author: Harpreet Kaur Walia. Email: dr.harpreet.17@gmail.com

\begin{abstract}
Introduction and Aim: Thyroid disorder, the most abundant endocrine disorder in the globe ranks second after diabetes mellitus. Because of immune resistance to thyroid gland, it leads to the development of hyperthyroidism and hypothyroidism. Autoantibodies against thyroid peroxidase (TPO) - a critical enzyme in the thyroid hormone biogenesis is responsible for thyroid autoimmunity and is increasingly found among type 2 diabetes mellitus (T2DM). So, the present study was designed to assess the serum anti-TPO antibodies among type 2 diabetes mellitus in hospital setting.

Materials and Methods: 100 clinically diagnosed type 2 diabetes mellitus was included with 50 age and sex matched apparently healthy controls in the age range 35-70 years. Mean age (in Years) of male and female T2DM cases had $57.40 \pm 5.93$ and $55.96 \pm 7.39$ respectively. Also, the male and female controls had mean age as $56.24 \pm 8.74$ and $54.20 \pm 8.90$ respectively.

Results: The mean glycated hemoglobin ( $\mathrm{HbA} 1 \mathrm{c})$ value among T2DM male and female cases was found to be $8.53 \pm 2.02 \%$ and $8.66 \pm 1.90 \%$ respectively. The mean value of serum TSH was found to be highly significant statistically among T2DM as compared to healthy controls, whereas mean value of serum anti-TPO antibodies was significant statistically among T2DM as compared to healthy controls. The occurrence of anti-TPO antibodies among T2DM was found to be 13 out of 100 (13\%) in the present study.

Conclusion: The association between serum TSH and anti-TPO antibodies among T2DM patients was found to be highly significant statistically. Thus, the existence of higher anti-TPO antibodies among T2DM points out the future development of functional thyroid problem in such patients.
\end{abstract}

Keywords: Thyroid peroxidase; thyroid autoimmunity; anti-TPO antibodies.

\section{INTRODUCTION}

$\mathrm{O}$ ut of 10, one adult will encompass diabetes by 2030; fact indicates that the figure of persons inhabiting with this disorder is anticipated to go up from 366 million in 2011 to 552 million by 2030, if no critical act is undertaken. This figure associates to nearly 3 new victims each 10 seconds or more or less 10 million each year. The figure of adult person having diabetes will amplify to $69 \%$ in developing nations and to $20 \%$ in developed nations in between 2010 and 2030 (1). It is estimated that in India, there are 50.8 million people with diabetes and the number is projected to rise to 70 million by 2025 (2). Endocrine dysfunctions are growing all over the world. Thyroid disorders are the amplest endocrine disorder in the world second only to DM (3). Auto immune thyroid disease (AITD) like Grave's disease (GD) and chronic autoimmune thyroiditis (cAIT) happens because of immune resistance to thyroid auto antigens leading to hyperthyroidism and hypothyroidism respectively (4). It is found that there is increased concentration of antibodies against thyroperoxidase (TPO)-a key enzyme involved in organification of iodine and coupling reaction in thyroid hormone production, thyroglobulin $(\mathrm{Tg})$ protein for iodine integration to form thyroid hormones and TSH receptor (TSH-R) in AITD (5). As the occurrence of AITD is clearly explained among type 1 diabetic patients, the risk of AITD in initially diagnosed T2DM is not known so far (6). As thyroid autoimmunity (TA) implies an unfavourable effect of hypothyroidism patients in insulin sensitivity, the reasonable association between T2DM and TA needs further explanation from both the clinical and research standpoints (7). The proof on the presence of circulating autoantibodies in T2DM in adults has progressively originated since late 1970 s, indicating that the type 2 diabetic patients of age $>65$ years have been associated with anti-GAD (glutamic acid decarboxylase - key enzyme involved in synthesis of $\gamma$-aminobutyric acid, inhibitory neurotransmitter found in neurone and endocrine pancreas) and/or antiinsulinoma protein 2 (IA-2) autoantibodies in $12 \%$ of 
patients (8). Further, the presence of circulating autoantibodies - a hallmark of autoimmune association in T2DM was reported in 1997 by Turner et $a l$, with the recognition of anti-GAD and IA-2 autoantibodies in large population of such patients recruited in UK prospective diabetes study (UKPDS) trial centres (9). Some clinical research resulted that higher prevalence of TPO antibodies was found in initially diagnosed T2DM patients that had GAD antibodies positive with respect to GAD antibodies negative T2DM patients (10). Also, the occurrence of TPO antibodies was significantly higher in T2DM patients that need insulin therapy than those not requiring insulin and suggested that both genetic and immunological factors facilitate impaired $\beta$-cell function among T2DM which is exemplified by increased thyroid antibodies and islet cell antibodies (ICAs; 11). Additionally, the possible phenomenon may include genetic relationship, psychological chronic stress and chronic infections for the increased incidence of AITD in T2DM (12).

The autoimmunity of thyroid gland among type 1 diabetes mellitus is well established with poor experimentation among type 2 diabetes mellitus, so, the present study is designed to assess the thyroid autoimmunity (anti-TPO antibodies) among type 2 diabetes mellitus.

\section{MATERIALS AND METHODS}

The present study was conducted in hospital setting by including 100 clinically diagnosed type 2 diabetic patients with 50 age and sex matched apparently healthy controls in the Department of Biochemistry in collaboration with Department of Medicine, Maharishi Markandeshwar Institute of Medical
Sciences and Research, Mullana-Ambala, Haryana, India. The patients were selected in the age range of 35-70 years by simple random sampling method from 2015-2017. The study was being approved by Institutional Ethics Committee. Any subject with the history of type 1 diabetes as well as below 35 years of age, on thyroid medication, on steroidal therapy, known case of thyroid disorder and on thyroid irradiation/surgery were excluded from the study. Demographic information of patients like age and sex were taken and detailed data related to present and past history, any illness and medication were collected as per the designed proforma.

Glycated hemoglobin (HbA1c) was measured by Ion Exchange Resin (13) method to confirm type 2 diabetes mellitus and serum thyroid stimulating hormone (TSH) and anti-thyroid peroxidase (AntiTPO) antibodies were measured by Microplate Chemiluminescence Immunoassay (CLIA) method (14). The obtained data were analysed using SPSS (Statistical Package for the Social Sciences) version 23.

\section{RESULTS}

The baseline characteristics in the present study were male T2DM cases had mean age as $57.40 \pm 5.93$ years and female T2DM cases had mean age as $55.96 \pm 7.39$ years. Also, the male controls had mean age as 56.24 \pm 8.74 years and that of female controls had $54.20 \pm$ 8.90 years. The mean $\mathrm{HbA1c}$ value among T2DM male cases was found to be $8.53 \pm 2.02 \%$ and that of T2DM female cases was found to be $8.66 \pm 1.90 \%$. The comparison of mean value of HbA1c, TSH and anti-TPO antibodies between type 2 diabetes mellitus and apparently healthy controls was shown (Table 1).

Table 1: Students' t-test showing the comparison of mean value, standard deviation and p value of HbA1c, TSH and anti-TPO antibodies between type 2 diabetes mellitus and apparently healthy controls

\begin{tabular}{|c|c|c|c|c|}
\hline PARAMETERS & GROUP & N & MEAN \pm S. D. & P VALUE \\
\hline \multirow{2}{*}{ Age } & T2DM cases & 100 & $56.76 \pm 8.94$ & 0.24 \\
& Controls & 50 & $55.22 \pm 6.71$ & Non-significant \\
\hline \multirow{2}{*}{ HbA1c } & T2DM cases & 100 & $8.60 \pm 1.95$ & 0.000 \\
\cline { 2 - 4 } & Controls & 50 & $4.75 \pm 0.66$ & Highly significant \\
\hline \multirow{2}{*}{ TSH } & T2DM cases & 100 & $4.45 \pm 6.03$ & 0.000 \\
& Controls & 50 & $1.89 \pm 0.855$ & Highly significant \\
\hline \multirow{2}{*}{ Anti-TPO antibodies } & T2DM cases & 100 & $31.44 \pm 96.80$ & 0.047 \\
\cline { 2 - 3 } & Controls & 50 & $11.91 \pm 7.15$ & Significant \\
\hline
\end{tabular}

In the present study, mean value of serum TSH was found to be highly significant statistically among T2DM as compared to healthy controls, whereas mean value of serum anti-TPO antibodies was significant statistically among T2DM as compared to healthy controls.

The occurrence of anti-TPO antibodies in the present study among type 2 diabetes mellitus was indicated in the figure 1 . The occurrence of anti-TPO antibodies among T2DM was found to be 13 out of $100(13 \%)$ in the present study.

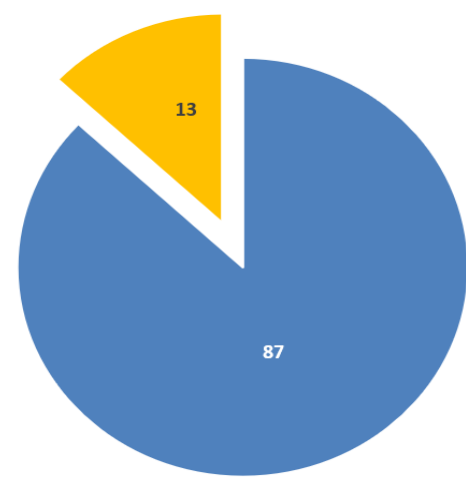


Fig. 1: Frequency of anti-TPO antibodies among 100 T2DM patients

The association of Serum TSH with anti-TPO antibodies among T2DM patients was found to be highly significant statistically (Table 2 ).

Table 2: Pearson's correlation of TSH with HbA1c and anti-TPO antibodies among T2DM patients.

\begin{tabular}{|c|c|c|c|}
\hline \multicolumn{2}{|c|}{ Parameter } & HbA1c & $\begin{array}{c}\text { Anti-TPO } \\
\text { antibodies }\end{array}$ \\
\hline \multirow{2}{*}{ TSH } & Pearson Correlation & 0.026 & $0.402^{* *}$ \\
\cline { 2 - 4 } & Sig. (2-tailed) & 0.801 & $\mathbf{0 . 0 0 0}$ \\
\hline
\end{tabular}

\section{DISCUSSION}

T2DM is worldwide growing burden which may be associated with the thyroid disorders in later life in general population. One study, carried out by Akbar et al. showed the relationship between thyroid disorder, thyroid autoimmunity, and T2DM and it was found that the prevalence of thyroid autoimmunity in diabetics was $10 \%$ and thyroid dysfunction was $16 \%$ among such patients (15). Diabetes mellitus and thyroid disorders equally impact on each other.

Mean HbA1c value was statistically highly significant among T2DM as compared to healthy control ( $p$ $<0.000)$. This finding was in accordance with the study carried out by Uppal et al and disclosed that there was statistically significant disparity in glycosylated hemoglobin among T2DM and control subject (16). There was increased concentration of serum TSH among T2DM in contrast to apparently healthy controls and the increase was also observed statistically highly significant $(\mathrm{p}<0.001)$. This finding was in accordance with the result displayed in the study done by Acharya et al (17). Similar finding was also shown by Panneerselvam et al., indicating that serum TSH was significantly elevated in T2DM than in normal individuals (18). However, study done by Islam et al., stated that there was no statistically significant disparity between type 2 diabetics and normal individuals (19). The mean serum anti-TPO antibodies were also increased among T2DM patients as compared to control showing statistically significant between these groups $(\mathrm{p}<0.05)$. This finding was in consistent with the study done by Elebrashy et al., in which anti-TPO was observed in $75.8 \%(347.14 \pm 244.87 \mathrm{IU} / \mathrm{ml})$ of diabetic cases against $7.4 \%(32.89 \pm 33.26 \mathrm{IU} / \mathrm{ml})$ of healthy subjects $(\mathrm{p}<0.001)(20)$.

In the current study, anti-TPO antibodies were observed to be $13 \%$ among T2DM cases. There was a variation in occurrence of autoimmune antibodies in T2DM patients. Akbar et al found that thyroid autoimmunity (positive anti-TPO antibodies) was noticed in $10 \%$ of T2DM subjects against $5 \%$ controls (15). In a study, it was observed that the occurrence of anti-thyroid antibodies positivity (anti-TPO and anti$\mathrm{Tg}$ antibodies) was elevated in T2DM than in controls. $10(10 \%)$ T2DM subjects had positive anti-TPO antibodies, while $1(1 \%)$ male non-diabetic control had positive anti-TPO antibody (21). It indicated the higher prevalence of autoimmune process among type 2 diabetic patients causing thyroid dysfunction.

In present study, there was not any statistically significant correlation between serum TSH and HbA1c. This outcome was in agreement with research carried out by Elebrashy et al., who also did not find significant association among glycosylated hemoglobin and TSH or anti-TPO antibodies in T2DM cases (20). However, Billic-Komarica et al., observed a significant positive link of glycosylated hemoglobin with TSH (22). In present study, statistically highly significant positive association of serum TSH with anti-TPO antibodies was seen ( $p$ $<0.01)$. This finding was in accordance with the result obtained in the study (20). This advocated the immune-mediated pathogenetic system involved in thyroid disorder in T2DM subjects, which is in agreement with Afkhami-Ardekani et al., study (23). In T2DM subjects with thyroid disorder, there is raised insulin resistance usually marked as deteriorated lipid parameters and poorly controlled glycemic status. Furthermore, it has been revealed that immunemediated thyroid disease links well with immunemediated damage of beta- cells (though not a noteworthy pathophysiology in T2DM), and this can lead to deterioration of glycemic status $(24,25)$.

\section{CONCLUSION}

Thyroid malfunction and diabetes are intimately linked with each other through a multifaceted interdependent biochemical interface. The simultaneous existence of both hormonal conditions impacts clinical scenario and laboratory outcomes directing screening, diagnostic and therapeutic approaches. If recognition of altered thyroid hormone parameters among diabetic individuals at any stage is not achieved, it may often be a prime reason of poor supervision of the subjects. The existence of anti-TPO antibodies is also marked among T2DM patients and the occurrence of higher TPO antibodies points out the future development of functional thyroid problem in such patients. Thus, regular screening of thyroid functioning, especially once or twice a year, TSH measurement and thyroid autoantibody is strongly recommended in all individuals with more focus on diabetic population to identify and manage the complications to reduce all cause of morbidity and mortality, thus providing better health care and longevity to the persons.

\section{LIMITATIONS AND FUTURE PERSPECTIVES}

The present study was confined to type 2 diabetic patients in hospital setting and so, further research design is needed to focus on large population-based longitudinal study to validate the association of thyroid functioning in clinical settings. The evaluation of serum thyroglobulin and anti-thyroglobulin antibodies will put beneficial role in displaying the 
thyroid immune-mediated association among diabetic patients. The incorporation of assessment of glutamic acid decarboxylase antibodies will also underline the immune-mediated interaction in the pathogenesis of diabetes mellitus and its possible role in autoimmune thyroid disease.

\section{ACKNOWLEDGMENT}

The authors express their gratitude and wish to thank Shree Tarsem Garg, Hon'ble Chancellor, MM University, Mullana (HR) and Solan (HP), and Mr. Sanjeev Garg, MM University Trust, Mullana, Ambala (HR) for their encouragement and ever available support in preparing manuscript.

\section{CONFLICT OF INTEREST}

The authors declare no conflict of interest.

\section{REFERECES}

1. Sah, N. K., Kaur, H., I, Sheikh., Sodhi, K. S., Singh, J., Bhaskar, N., et al., Microalbuminuria as an independent risk factor of cardiovascular disease in type 2 diabetes mellitus. Journal of Pharmaceutical and Biomedical Sciences. 2013; 32(32): 1324-1328.

2. Baruah, M. P., Kalra, S., Unnikrishnan, A. G., Raza, S. A., Somasundaram, S., John, M., et al., Management of hyperglycemia in geriatric patients with diabetes mellitus: South Asian consensus guidelines. Indian Journal of Endocrinology and Metabolism. 2011; 15: 75-90.

3. Heuck, C. C., Kallner, A., Kanagasabapathy, A. S., Riesen, W. Diagnosis and monitoring of the disease of the thyroid. WHO Document; 2012: 8-9.

4. Collins, J., Gough, S. Autoimmunity in thyroid disease. European Journal of Nuclear Medicine and Molecular Imaging. 2002; 29: 417-424.

5. Nielsen, C. H., Hegedüs, L., Leslie, R. G. Autoantibodies in autoimmune thyroid disease promote immune complex formation with self-antigens and increase B cell and CD4+ T cell proliferation in response to self-antigens. European Journal of Immunology. 2004; 34: 263-272.

6. Matejková-Behanová, M., Zamrazil, V., Vondra, K., Vrbíková, J., Kucera, P., Hill, M., et al., Autoimmune thyroiditis in non-obese subjects with initial diagnosis of Type 2 diabetes mellitus. Journal of Endocrinological Investigation. 2002; 25: 779-784.

7. Toulis, K., Tsekmekidou, X., Potolidis, E., Didangelos, T., Gotzamani-Psarrakou, A., Zebekakis, P., et al., Thyroid autoimmunity in the context of type 2 diabetes mellitus: implications for vitamin D. International Journal of Endocrinology. 2015; 2015: 1-5.

8. Pietropaolo, M., Barinas-Mitchell, E., Pietropaolo, S. L., Kuller, L. H., Trucco, M. Evidence of islet cell autoimmunity in elderly patients with type 2 diabetes. Diabetes. 2000; 49: 32-38.

9. Turner, R., Stratton, I., Horton, V., Manley, S., Zimmet, P., Mackay, I.R., et al., UKPDS 25: autoantibodies to islet-cell cytoplasm and glutamic acid decarboxylase for prediction of insulin requirement in type 2 diabetes. UK Prospective Diabetes Study Group. Lancet. 1997; 350: 1288-1293.

10. Gambelunghe, G., Forini, F., Laureti, S., Murdolo, G., Toraldo, G., Santeusanio, F., et al., Increased risk for endocrine autoimmunity in Italian type 2 diabetic patients with GAD65 autoantibodies. Clinial Endocrinology. (Oxf.). 2000; 52: 565-573.

11. Groop, L., Miettinen, A., Groop, P. H., Meri, S., Koskimies, S., Bottazzo, G. F. Organ-specific antigens as markers for beta-cell destruction in patients with type II diabetes. Diabetes. 1988; 37: 99-103.
12. Schroner, Z., Lazurova, I., Petrovicova, J. Autoimmune thyroid diseases in patients with diabetes mellitus. Bratislavske Lekarske Listy. 2008; 109(3): 125-129.

13. Nathan, D. M., Singer, D. E., Hurxthal, K., Goodson, J. D. The clinical information value of the glycosylated hemoglobin assay. The New England Journal of Medicine. 1984; 310(6): 341-346.

14. Burtis, C. A., Ashwood, E. R., Bruns, D. E. Teitz Textbook of Clinical Chemistry and Molecular Diagnostics. $4^{\text {th }}$ edition. New Delhi: Saunders; 2008.

15. Akbar, D. H., Ahmed, M. M., Al-Mughales, J. Thyroid dysfunction and thyroid autoimmunity in Saudi type 2 diabetics. Acta Diabetologica. 2006; 43: 14-18.

16. Uppal, V., Vij, C., Bedi, G.K., Vij, A., Banerjee, B.D. Thyroid disorders in patients of type 2 diabetes mellitus. Indian Journal of Clinical Biochemistry. 2013; 28(4): 336341.

17. Acharya, A., Shah, P. B., Chitkara, E., Shrestha, S. Evaluation of thyroid hormones level in patients with type 2 diabetes mellitus as compared to normal individuals in Nepal. International Journal Health Sciences and Research. 2017; 7(1): 79-85.

18. Ramesh, V., Geetha, R., Anitha, D., Swamy, N. R. V. K., Panneerselvam, T. T. The study of thyroid dysfunction among type 2 diabetic patients. International Journal of Current Research and Academic Review. 2015; 3(9): 14-18.

19. Islam, S., Yesmine, S., Khan, A. S., Alam, N. H. A comparative study of thyroid hormone levels in diabetic and nondiabetic patients. Southeast Asian Journal of Tropical Medicine and Public Health. 2008; 39(5): 913-916.

20. Elebrashy, I. N., Meligi, A. E., Rashed, L., Salam, R. F., Youssef, E., Fathy, S. A. Thyroid dysfunction among type 2 diabetic female Egyptian subjects. Therapeutics and Clinical Risk Management. 2016; 12: 1757-1762.

21. Nwokolo, H. I., Meludu, S. C., Dioka, C. E., Onah, C. E., Ikemefuna, F. O., Obiageli, B., et al., The prevalence of thyroid dysfunction and thyroid autoantibodies among type 2 diabetic patients in Nnewi, Southeastern Nigeria. Journal of Medical Science and Clinical Research. 2014; 2(4): 646-653.

22. Billic-Komarica, E., Beciragic, A., Junuzovic, D. The importance of $\mathrm{HbA} 1 \mathrm{c}$ control in patients with subclinical hypothyroidism. Materia Socio Medica. 2012; 24(4): 212219.

23. Afkhami-Ardekani, M., Rashidi, M., Shojaoddiny-Ardekani, A. Prevalence of thyroid autoantibodies in type 2 diabetic patients. Iranian Journal of Diabetes and Obesity. 2012; 4(1): $1-6$.

24. Chehade, J. M., Gladysz, M., Mooradian, A. D. Dyslipidaemia in type 2 diabetes: Prevalence, pathophysiology, and management. Drugs. 2013; 3(4): 327339.

25. Primo, M. E., Niepomniszcze, H., Poskus, E., Sala, M. S., Guaita, S. S., Sica, M. P., et al., Frequency of pancreatic betacell autoimmunity markers in patients with autoimmune thyroid disease. Medicina Buenos Aires. 2008; 68(1): 37-42. 